\title{
Phase Separation Phenomena in Solutions of Poly(2,6-Dimethyl-1,4-phenyleneoxide) in Mixtures of Trichloroethylene, 1-Octanol, and Methanol: Relationship to Membrane Formation*
}

\author{
J. G. WIJMANS, ${ }^{\dagger}$ H. J. J. RUTTEN, and C. A. SMOLDERS, Department \\ of Chemical Technology, Twente University of Technology, P.O. Box 217, \\ 7500 AE Enschede, the Netherlands
}

\section{Synopsis}

The phase boundaries in the quaternary system consisting of the polymer poly(2,6-dimethyl1,4-phenyleneoxide) (PPO'), the solvent trichloroethylene (TCE), and the nonsolvents 1-octanol $(\mathrm{OcOH})$ and methanol $(\mathrm{MeOH})$ are determined. The kinetics of crystallization are investigated by pulse-induced critical scattering. The formation and properties of PPO membranes are discussed in relation to the phase separation phenomena.

\section{INTRODUCTION}

Polymeric synthetic membranes are usually made by the phase inversion process. The mechanism of this process is the induction of phase separation in a polymer solution through a change in the composition of the solution. The interplay of the phase separation phenomena and the rate of change in composition determines the membrane structure. In most cases an asymmetric structure is obtained: a very thin $(0.1-0.5 \mu \mathrm{m})$ and dense top layer is supported by a porous sublayer $0.1-0.2 \mathrm{~mm}$ thick. The relationship between the preparation procedure and the ultimate membrane structure has been investigated by a number of research groups, and the approach adopted in our laboratory was extensively discussed in two reviews. ${ }^{1,2}$ This mechanism of formation is recapitulated briefly in the Theory section.

A study was carried out by Broens et al. ${ }^{3}$ to prepare ultrafiltration membranes from poly(2,6-dimethyl-1,4-phenyleneoxide) (PPO). The polymer PPO was selected since it has good chemical and physical properties. It appeared that membranes with promising ultrafiltration properties are obtained if a casting solution of $10 \% \mathrm{PPO}$ in a $78 \% / 22 \%$ mixture of trichloroethylene (TCE) and 1-octanol $(\mathrm{OcOH})$ is immersed in a coagulation bath containing methanol $(\mathrm{MeOH})$. The concentrations are expressed as weight percentages. The addition of $\mathrm{OcOH}$ to the casting solution is essential to obtain membranes with an acceptable water permeability. If the TCE/OcOH mixture

* A part of this work was presented at the First Europe-Japan Congress on Membranes and Membrane Processes, Stresa, Italy, June 18-22, 1984.

† Present address: Membrane Technology and Research, Inc., 1030 Hamilton Court, Menlo Park, CA 94025.

: PPO is a registered trademark of the General Electric Company.

Journal of Polymer Science: Polymer Physics Edition, Vol. 23, 1941-1955 (1985)

(C) 1985 John Wiley \& Sons, Inc.

CCC 0098-1273/85/091941-15\$04.00 
contains less than $18 \%$ OcOH, the membrane is not permeable to water. It was suggested ${ }^{3}$ that the addition of $\mathrm{OcOH}$ increases the ability of the PPO molecules to crystallize and thus leads to a more grainy structure in the top layer and that the water permeation during ultrafiltration occurs through the voids of the densely packed crystalline nodules.

In this paper we determine phase equilibria of the quarternary system $\mathrm{PPO} / \mathrm{TCE} / \mathrm{OcOH} / \mathrm{MeOH}$ and the kinetics of the PPO crystallization in this system. These data will be discussed in relation to the formation and properties of PPO membranes.

\section{THEORY}

\section{Mechanism of Membrane Formation ${ }^{1,2}$}

Two different types of phase separation are thought to be responsible for the asymmetry of the membranes: (i) gelation (possibly induced by crystallization) for the formation of the skin; and (ii) liquid-liquid demixing followed by gelation of the polymer-rich phase, for the formation of the porous substructure.

The two different types of phase separation are the result of different changes in composition characteristic for each layer. In Figure 1 a schematic ternary phase diagram is presented and the changes in composition are visualized by so-called coagulation paths.

If gelation occurs by formation of crystalline crosslinks, the solution/gel transition is a true thermodynamic equilibrium and in combination with liquid-liquid demixing it will create a three-phase region in the phase diagram as shown in Figure 2. Within the three-phase region all compositions will split up into the three compositions that form the corners of the three-phase triangle; that is, if the equilibrium state is reached. The entry of the three-phase region is a dynamic process, i.e., a change in temperature or composition, and the kinetics of both gelation and liquid-liquid demixing will be important. Except for high polymer concentrations, liquidliquid demixing will in general be faster than gelation.

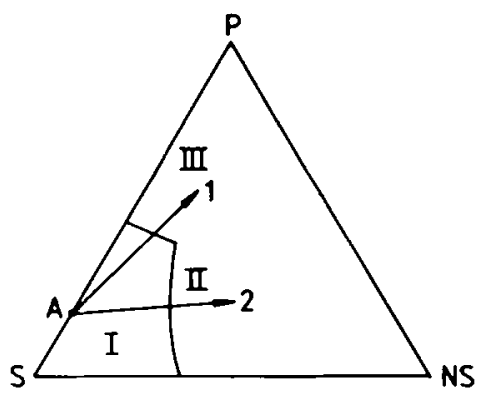

Fig. 1. Ternary phase diagram. I: homogeneous solution; II: liquid-liquid demixing; III gel area. The arrows 1 and 2 are possible coagulation paths characteristic of the top layer and the porous substructure, respectively. 


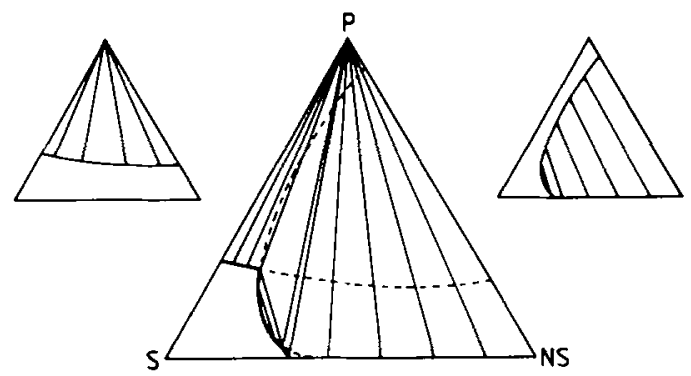

Fig. 2. Phase diagram of a ternary system with a solubility gap in the liquid phase and crystalline component $P$. The solubility gap (right) intersects the melting curve (left) and a three-phase region is formed.

\section{Kinetics of Crystallization}

Crystallization takes place by formation of stable nuclei and subsequent growth of these nuclei, the so-called nucleation and growth mechanism. A relation widely used to describe the kinetics of isothermal growth is the Avrami equation 4

$$
X=1-\exp \left(-a t^{n}\right)
$$

where $X$ is the degree of conversion, $a$ is the growth constant, $t$ is the time, and $n$ is the Avrami exponent. In the early stage of crystallization when the degree of conversion is small, we can write

$$
X=a t^{n}
$$

or

$$
V_{n}=b t^{n}
$$

where $V_{n}$ is the volume of a nucleus which was formed at time $t=0$ and $b$ is the growth constant of the nucleus. If all nuclei are formed at $t=0$ and if their number remains constant during the growth period, the value of the Avrami exponent is determined by the mechanism of growth and the shape of the nuclei. In the case of spherical nuclei, $n$ has a value of $\frac{3}{2}$ for diffusion-controlled growth and a value of 3 for interfacially controlled growth. ${ }^{5}$ Generation of nuclei during the growth period will shift the apparent value of $n$ in eq. (2a) to higher values.

If crystallization is induced by a change in the stability conditions at time $t=0$, the number of nuclei at that moment will be zero. There is a transient period in which the steady-state nucleus concentration is reached. A relation proposed to describe the nucleation frequency in this period is ${ }^{6}$

$$
F_{\imath}=F \exp (-\tau / t)
$$


where $F_{t}$ is the nucleation frequency at time $t\left(F_{t}=F\right.$ at $\left.t=\infty\right)$ and $\tau$ is the time constant characteristic of the transient period. The time constant is related to the driving force for crystallization in the following ways:

$$
\tau \propto \Delta G_{v}^{-4}
$$

or

$$
\tau \propto\left[\ln \left(C_{0} / C_{e}\right)\right]^{-4}
$$

where $\Delta G_{v}$ is the standard free energy of crystallization, $C_{0}$ is the solution concentration of the crystallizing component, and $C_{e}$ is the equilibrium or saturation concentration. Equation (4b) is derived from eq. (4a) with the assumption that the activity coefficient is independent of the concentration. The driving force $\Delta G_{v}$ can also be expressed as the degree of undercooling:

$$
\Delta G_{v} \propto T_{e}-T \text { or } \tau \propto\left(T_{e}-T\right)^{-4}
$$

where $T$ is the actual crystallization temperature and $T_{e}$ is the equilibrium or melting temperature. In eq. (5) the effect of the temperature on the diffusion, which plays a role in the nucleation frequency, is ignored. This implies that eq. (5) will hold for limited temperature ranges only.

A simplification of the $F_{t}$ function of eq. (3) is a step function in which the nucleation frequency jumps from zero to $F$ at time $t=t^{\prime}$. The volume of each nucleus at time $t$ in that case is given by

$$
V_{n}=b\left(t-t^{\prime}\right)^{n}
$$

It is obvious that the so-called induction time $t^{\prime}$ is related to the time constant $\tau$. Equation (3) describes the transient period with a dimensionless time scale $t / \tau$. We will therefore assume that $t^{\prime}$ is proportional to $\tau$ and thus that

$$
t^{\prime} \propto\left[\ln \left(C_{0} / C_{e}\right)\right]^{-4}
$$

or

$$
t^{\prime} \propto\left(T_{e}-T\right)^{-4}
$$

\section{Light Scattering}

The light scattering of nuclei with diameters small compared to the wavelength of the light is given by the equation of Rayleigh?:

$$
I_{\theta}=\text { (const) } I_{0}\left[\left(n_{n}^{2}-n_{0}^{2}\right) / n_{0}^{2}\right]^{2} V_{n}^{2} N_{n}\left(1+\cos ^{2} \theta\right)
$$

where $I_{\theta}$ is the intensity of light scattered at angle $\theta, I_{0}$ is the intensity of the incident light, $n_{n}$ and $n_{0}$ are the refractive index of the nucleus and the surrounding medium, respectively, and $N_{n}$ is the number of nuclei per unit volume. 
If we restrict the analysis to the early stage of crystallization, i.e., the nuclei are assumed to be small and to exhibit Rayleigh scattering, combination of eqs. (6) and (8) gives

$$
\mathrm{I}_{\theta}=\mathrm{K}\left(\mathrm{t}-\mathrm{t}^{\prime}\right)^{2 \mathrm{n}}
$$

where $K$ is the growth or rate constant. The intensity versus time curves are in this way characterized by the exponent $n$ (the mechanism of growth), the induction time $t^{\prime}$ (formation of stable nuclei), and the growth constant $K$ (determined by the growth rate and the number of nuclei).

\section{EXPERIMENTS}

\section{Materials}

PPO was kindly supplied by General Electric Plastics, Bergen op Zoom, The Netherlands. The sample is characterized by $M_{n}=21,000$ and $M_{w}=$ 44,000 (measured by high-performance liquid chromatography). The solvents and nonsolvents used are of reagent grade and were used without further purification.

\section{Cloud Points}

Cloud points were measured by using a method described earlier. ${ }^{8}$ The location of the demixing gap was determined at a temperature of $25^{\circ} \mathrm{C}$ in pseudoternary systems with fixed ratios of $\mathrm{OcOH}$ and $\mathrm{MeOH}$. The cloud points were detected by monitoring the turbidity of the polymer solutions during a slow cooling run.

\section{Differential Scanning Calorimetry}

Appropriate amounts of PPO and the nonsolvent/solvent mixture were weighed in aluminum sample pans and the pans were sealed. The solutions were homogenized at a temperature of $90^{\circ} \mathrm{C}$ for at least two days. Only sample pans which showed no loss of weight during that period were used in the experiments. The DSC employed is a Perkin-Elmer DSC 2 apparatus.

\section{Pulse-Induced Critical Scattering}

This method has been developed by Gordon and co-workers ${ }^{9,10}$ to investigate spinodal or critical demixing in polymer solutions. The experimental setup is also suited to the investigation of crystallization kinetics in the early stage after a sudden change in temperature, as was demonstrated by Koenhen. ${ }^{11}$ The experiments are carried out in the following way.

A polymer mixture is placed in a very thin capillary glass tube with inner and outer diameters of 1.0 and $1.5 \mathrm{~mm}$, respectively. The tube is sealed and its contents are homogenized at an elevated temperature $\left(90^{\circ} \mathrm{C}\right.$ normally). The tube is brought into a thermostat bath $\left(25^{\circ} \mathrm{C}\right.$ normally) by means of a stepper motor and is thereby positioned exactly in a laser beam (see Fig. 3 ). The formation of crystalline entities in the polymer solution causes 


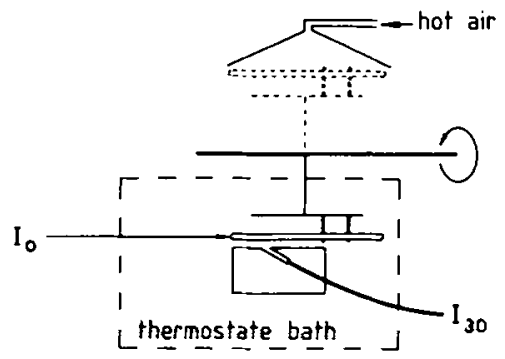

Fig. 3. PICS apparatus. The capillary tube is attached to a stepper motor axis and is moved at time $t=0$ from the up position (hot air heating) to the down position (thermostat). The scattered light is guided through an optical fiber to a lightsensitive diode outside the bath.

scattering of the laser light and the scattering intensity at an angle of $30^{\circ}$ is measured in time. Temperature control, initiation of the stepper motor, and storage and analysis of the intensity data are performed with the help of a microcomputer.

\section{Membranes}

Membranes were prepared by casting a solution on a glass plate and then immersing this film in a coagulation bath containing methanol. The top surface of the membranes (the bath/film interface) is examined with a Jeol JSM 35 CF scanning electron microscope after washing with water and air drying of the membranes.

\section{RESULTS AND DISCUSSION}

\section{Crystallinity of PPO as Received}

Figure 4 displays the DSC thermogram upon heating of the PPO polymer as received (run $\mathrm{I}$ ) and the DSC thermogram upon reheating (run II). Run I shows a broad melting peak with a maximum at $245^{\circ} \mathrm{C}$, which is preceded by an exotherm at $220^{\circ} \mathrm{C}$. The exotherm is believed to be a recrystallization phenomenon. The sample is cooled rapidly from 300 to $50^{\circ} \mathrm{C}$ and is then reheated. Run II exhibits no endotherm or exotherm, but only a glass transition at $220^{\circ} \mathrm{C}$. This implies that this time the sample is completely amor-

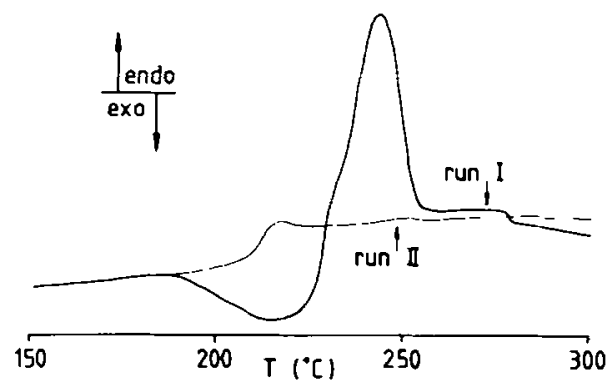

Fig. 4. DSC thermogram of the PPO as received (run I) and upon reheating (run II). Heating range: $20^{\circ} \mathrm{C} / \mathrm{min}$. 
phous and the same observation is made if the cooling rate is slow. These results are in agreement with the findings of Karasz and $O^{\prime}$ Reilly, ${ }^{12}$ although they did not detect such a pronounced recrystallization effect. From these experiments we conclude that PPO as received is partly crystalline but does not crystallize easily from the melt.

\section{Phase Diagram}

The cloud-point compositions at $25^{\circ} \mathrm{C}$ have been determined for five different ratios of $\mathrm{OcOH}$ and $\mathrm{MeOH}$ (see Fig. 5). The rate of cooling in the turbidity experiments was $1^{\circ} \mathrm{C} / 10 \mathrm{~min}$. It is clear that $\mathrm{MeOH}$ is a stronger nonsolvent for PPO than $\mathrm{OcOH}$. Cloud-point measurements usually yield the location of the liquid-liquid demixing gap in the phase diagram. However, in the binary PPO/TCE system no liquid-liquid demixing but rather crystallization takes place, so the phase boundaries displayed in Figure 5 are of a miscellaneous nature. It is expected that crystallization is responsible for the boundaries at high PPO concentrations and liquid-liquid demixing for the boundaries at high nonsolvent concentrations. The exact determination of the two regions is not possible as liquid-liquid demixing in this system is immediately followed by crystallization in the concentrated phase. This implies that (i) all cloud-point compositions display a crystallization exotherm upon cooling in DSC experiments, and (ii) separation of demixed systems into two liquid equilibrium phases (a proof of liquid-liquid phase separation) is not possible. It may be possible that a very accurate determination of the cloud-point curves would reveal the discontinuity which is suggested by Figure 2 to accompany the transistion from gelation to liquid-liquid demixing. The fact that PPO crystallizes from solutions with cloud-point compositions and not from the pure PPO melt (see Fig. 4) is probably the result of the poor crystallization kinetics present in the melt. ${ }^{12}$

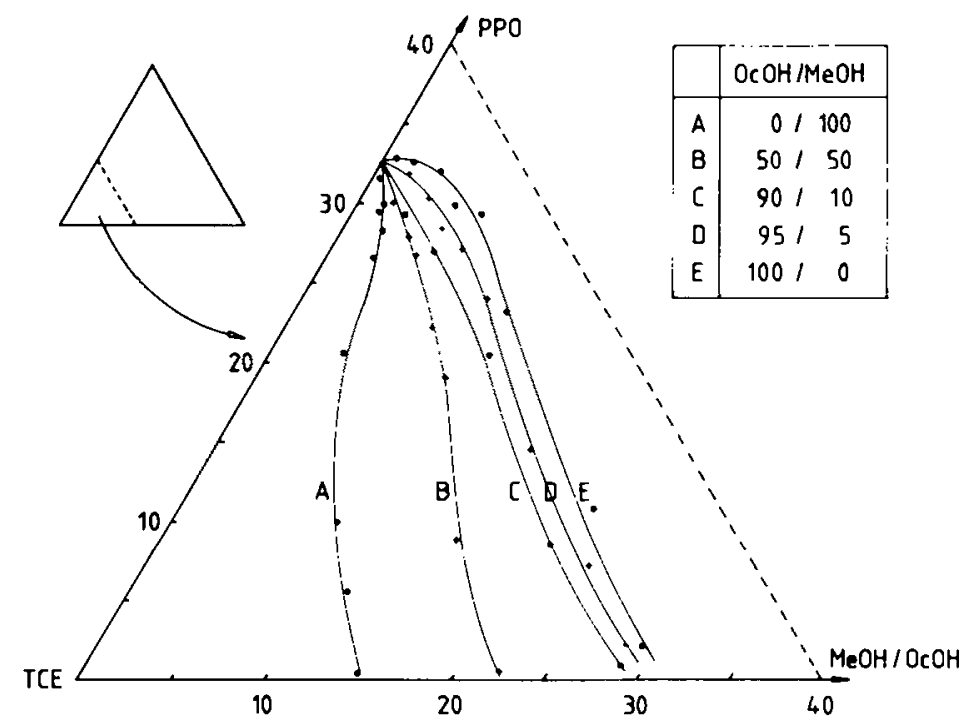

Fig. 5. Cloud-point compositions at $25^{\circ} \mathrm{C}$ for five pseudo-ternary systems. 
To illustrate that at least at lower PPO concentrations liquid-liquid demixing occurs, the following experiment was conducted. Ternary solutions of PPO, TCE, and $\mathrm{OcOH}$ were prepared and were cast on a glass plate and subsequently evaporated in a nitrogen atmosphere containing $\mathrm{OcOH}$ vapor. If it is assumed that in the first stage of evaporation only the TCE leaves the film (the boiling points of TCE and $\mathrm{OcOH}$ being respectively 74 and $194^{\circ} \mathrm{C}$ ), we can evaluate the change in composition for each solution as is shown in Figure 6. After one day the films are completely dried in a vacuum oven and the structure of the surfaces is examined with the electron microscope (see Fig. 7 for the micrographs). From experiment No. 1 to No. 12 the PPO concentration at the moment the phase boundary is crossed, increases. We see that in the first four experiments liquid-liquid phase separation has occurred at the polymer-poor side of the critical point (i.e., more or less densely packed solidified nuclei of the concentrated polymer phase have formed). In experiment No. 6 the demixing has taken place in the polymer-rich phase of the critical point, i.e., solidification of the concentrated polymer phase surrounding the nucleated dilute phase. From experiment No. 6 to 12 the structure becomes denser although there is some variation. These results suggest that the critical point in this ternary system is at a PPO concentration of about $10 \%$.

\section{Kinetics of Crystallization}

The kinetics of crystallization at $25^{\circ} \mathrm{C}$ have been investigated for eight different ratios of $\mathrm{TCE}, \mathrm{OCOH}$, and $\mathrm{MeOH}$, with $\mathrm{PPO}$ concentrations varying from 30 to $40 \%$ (see Table I). The $\mathrm{OcOH}$ and $\mathrm{MeOH}$ contents are kept low in order to avoid the possibility of liquid-liquid demixing in the samples.

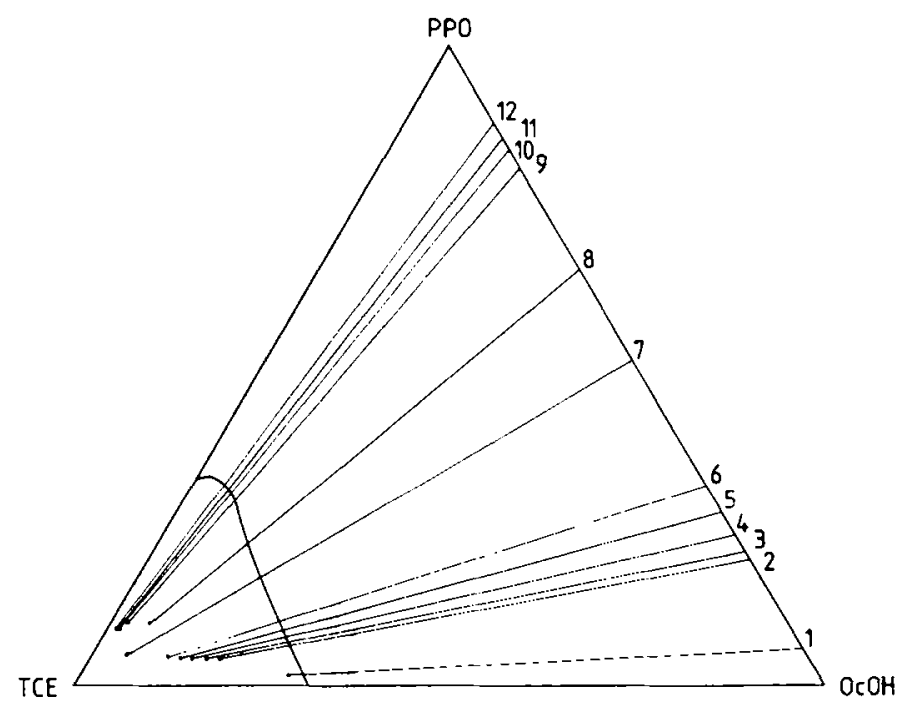

Fig. 6. Initial compositions ( ) of ternary casting solutions. The straight lines represent the change in composition if only TCE evaporates. The experiments are numbered 1-12; see also text. 


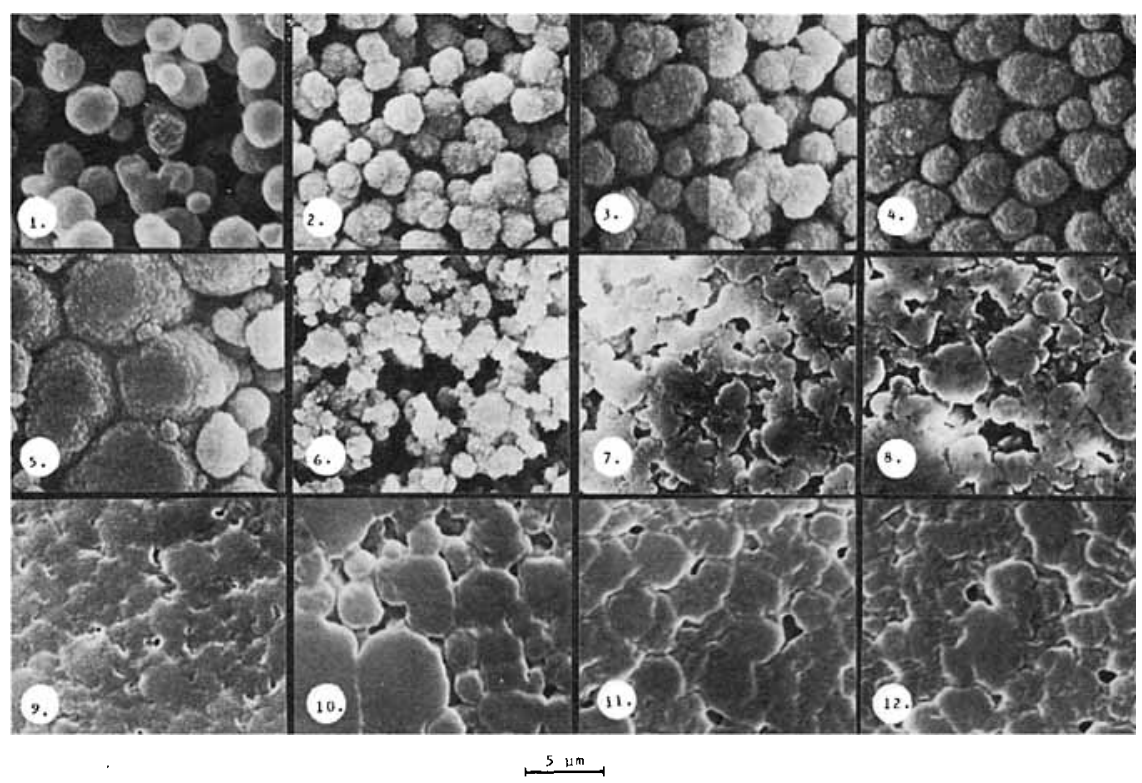

Fig. 7. Micrographs of top surface of PPO films. See text for preparation procedure. The numbers correlate with those in Figure 6.

An example of a light-scattering curve is given in Figure 8. The graph displays a distinct induction time before scattering is observed. The maximum in the curve is probably due to a change in the mode of scattering as the crystallization proceeds. The scattering intensity may decrease with increasing particle diameter if the diameter is large compared with the wavelength of the light. If one uses eq. (9) in the analysis of the scattering curves, one must be sure that the degree of conversion is low and that Rayleigh scattering occurs. To ascertain this, the point of inflexion in the intensity versus time curve is identified, and eq. (9) is applied to the first part of the curve where $I$ is less than one-third of its value at the point of inflection. ${ }^{11}$

All intensity versus time plots were analyzed to obtain values for $K, t^{\prime}$, and $n$. The value of $n$ is close to $\frac{3}{2}$ for all experiments, so the growth of the nuclei is diffusion controlled. The same observation was made by Koenhen ${ }^{11}$ for crystallization in the system of PPO and toluene. Setting $n$ equal to $\frac{3}{2}$, we computed the values of $K$ and $t^{\prime}$ using a least-squares method. In each

TABLE I

Compositions of TCE/OcOH/MeOH Mixtures Used in the PICS Experiments; PPO Concentrations Vary from 30 to $40 \%$

\begin{tabular}{rrr}
$100 / 0 / 0$ & $99 / 0 / 1$ & $98 / 0 / 2$ \\
& $98 / 1 / 1$ & \\
$98 / 2 / 0$ & $97 / 2 / 1$ & $96 / 2 / 2$ \\
$95 / 5 / 0$ & & \\
\hline
\end{tabular}




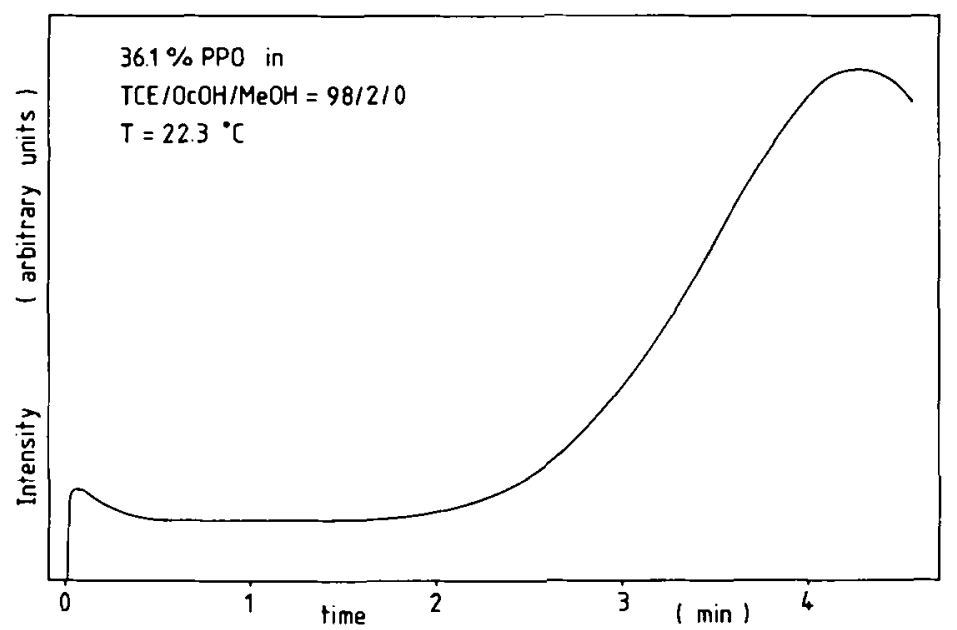

Fig. 8. Intensity of scattered laser light ( $30^{\circ}$ angle) as a function of time in a PICs experiment.

homologous series the growth constant increases and the induction time decreases with increasing PPO concentration. This is expected as the driving force for crystallization increases with increasing PPO concentration. With eq. (7a) the induction time data yield information on the equilibrium (saturation) PPO concentration in each system at $25^{\circ} \mathrm{C}$. An example of a $t^{\prime-0,25}$ vs. $\ln \left(C_{0}\right)$ plot is given in Figure 9 and the obtained values for $C_{e}$ are listed in Table II. The saturation concentrations are 4-5\% lower than the cloudpoint compositions if the rate of cooling is $1^{\circ} \mathrm{C} / 10 \mathrm{~min}$. Agreement between $C_{e}$ and the cloud-point composition is reasonably good if the cooling rate is decreased to $1^{\circ} \mathrm{C} / 24 \mathrm{~h}$.

In Figures 10 and 11 the growth constant $K$ and the induction time $t^{\prime}$ are plotted as a function of the percentage supersaturation, i.e., the actual

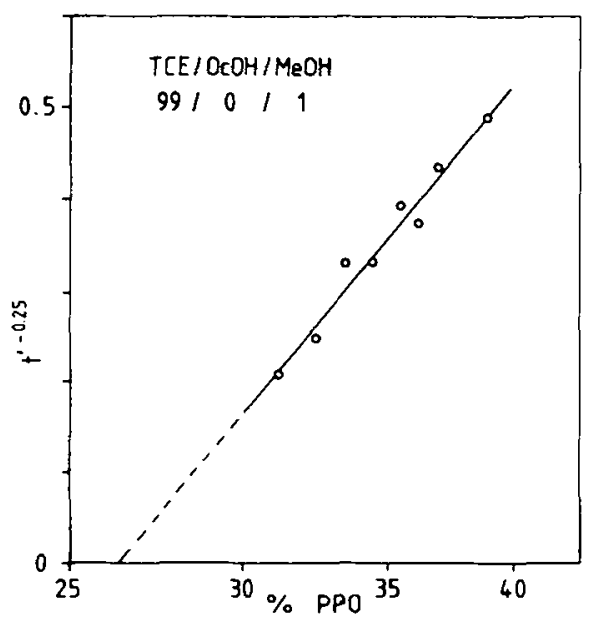

Fig. 9. Induction time, $t^{\prime}$ (in s) as a function of PPO concentration at $25^{\circ} \mathrm{C}$. 
TABLE II

PPO Saturation Concentrations Obtained from Induction Times [Eq. (7a)]

\begin{tabular}{clll}
\hline $\begin{array}{c}\text { TCE } / \mathrm{OCOH} / \\
\mathrm{MeOH}\end{array}$ & $C_{\mathrm{e}}(\% \mathrm{PPO})$ & $\begin{array}{c}\mathrm{TCE} / \mathrm{OcOH} / \\
\mathrm{MeOH}\end{array}$ & $C_{\mathrm{e}}(\% \mathrm{PPO})$ \\
\hline $100 / 0 / 0$ & $28.0 \pm 2$ & $95 / 5 / 0$ & $26.5 \pm 1.5$ \\
$99 / 0 / 1$ & $26.3 \pm 0.3$ & $98 / 1 / 1$ & $26.0 \pm 1$ \\
$98 / 0 / 2$ & $23.3 \pm 0.5$ & $97 / 2 / 1$ & $25.3 \pm 0.5$ \\
$98 / 2 / 0$ & $28.0 \pm 2$ & $96 / 2 / 2$ & $22.4 \pm 0.5$ \\
\hline
\end{tabular}

PPO concentration minus $C_{e}$ In this way we correct for the change in equilibrium concentration and we are able to evaluate the effect of $\mathrm{OcOH}$ and $\mathrm{MeOH}$ on the kinetics of the PPO crystallization. The data are considerably scattered in Figures 10 and 11, but it seems that no solvent/nonsolvent system deviates systematically from the others. Consequently it is concluded that no systematic effect of $\mathrm{OcOH}$ and/or $\mathrm{MeOH}$ on the nucleation and growth process of PPO crystallization is observed. The growth constant $K$ is determined by the rate of growth of the nuclei and the number of nuclei present per unit volume [see eqs. (8) and (9)]. To be able to distinguish these two quantities, one needs an independent method to determine the number of nuclei. Preliminary experiments with an optical microscope were not successful in this respect.

For two compositions the crystallization kinetics have been studied as a function of temperature. An increase in temperature will decrease the driving force for crystallization and thus will decrease $K$ and increase $t^{\prime}$. On

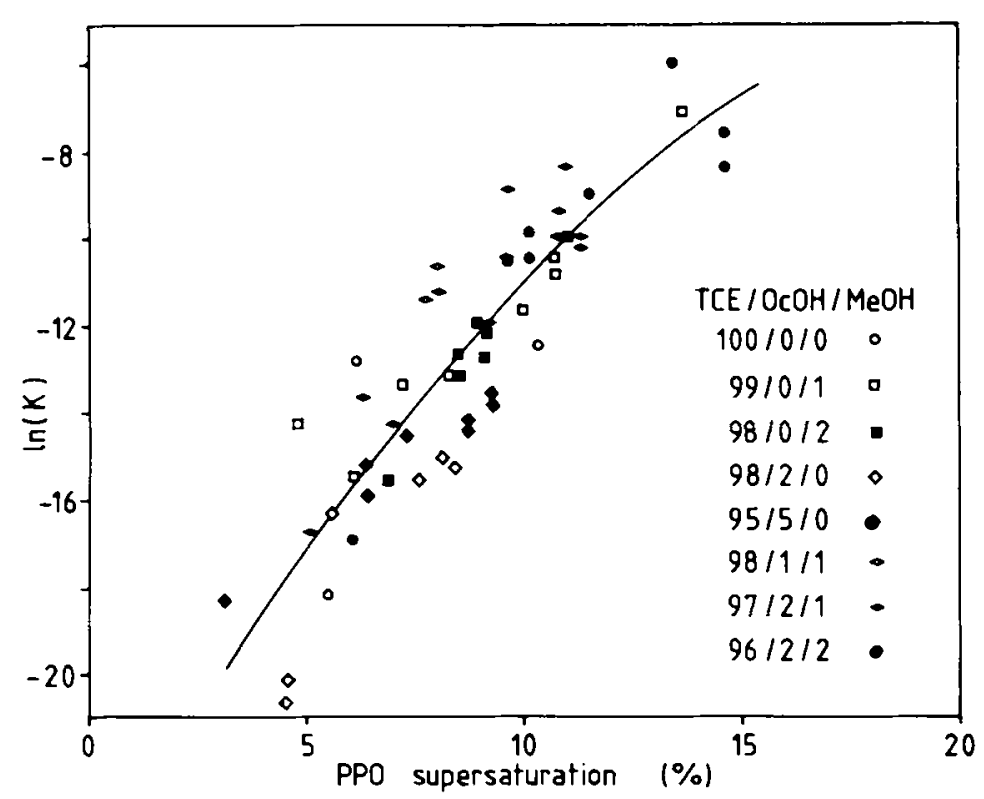

Fig. 10. Growth constant $K$ (in arbitrary units) as a function of PPO supersaturation $\left(C_{0} . C_{\mathrm{e}}\right)$ at $25^{\circ} \mathrm{C}$. 


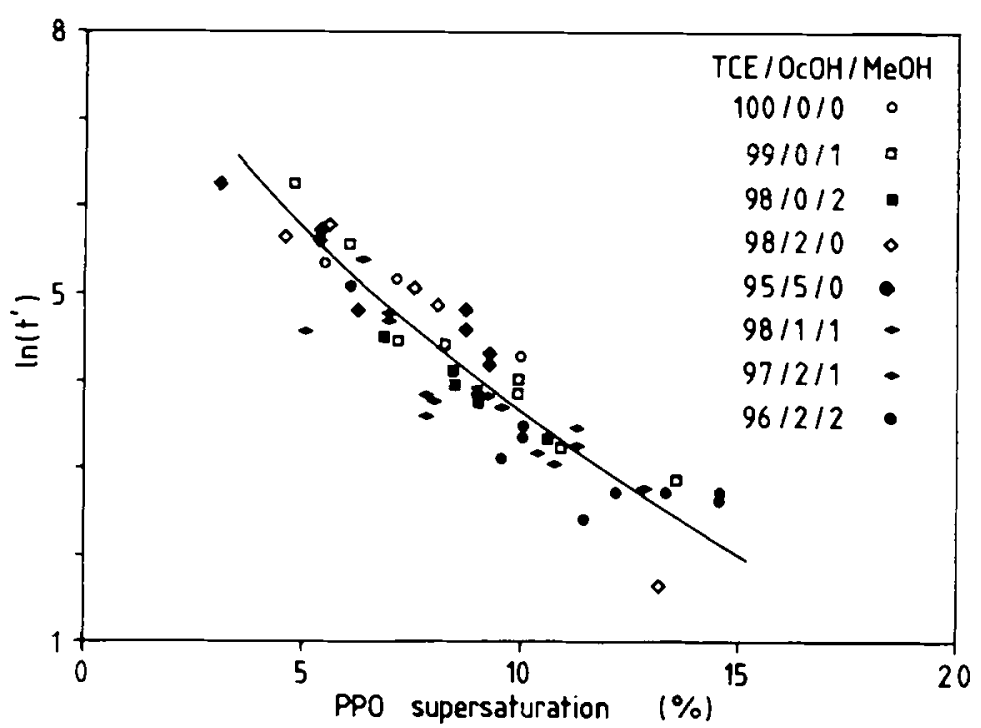

Fig. 11. Induction time $t^{\prime}$ (in s) as a function of PPO supersaturation $\left(C_{0}-C_{d}\right.$ at $25^{\circ} \mathrm{C}$.

the other hand, the diffusion coefficient increases with increasing temperature, which favors both nucleation and growth of the nuclei. The data displayed in Figure 12 show that the effect on the driving force is dominant: $K$ and $t^{\prime}$ respectively decrease and increase with increasing temperature. The straight lines in the $t^{\prime-0.25} \mathrm{vs}$. $T$ plot are drawn according to eq. (7b). Analysis of data published previously by Koenhen ${ }^{11}$ shows that the dependence of $t^{\prime}$ on $T$ is very well described by eq. (7b) (crystallization in PPOtoluene solutions).

\section{PPO Membranes}

In previous work, PPO membranes have been prepared by Broens et al. ${ }^{3}$ and by Buys et al. ${ }^{13}$ by immersing a PPO/TCE/OcOH film in a $\mathrm{MeOH}$ coagulation bath. At a constant polymer concentration of $10 \%$ the amount
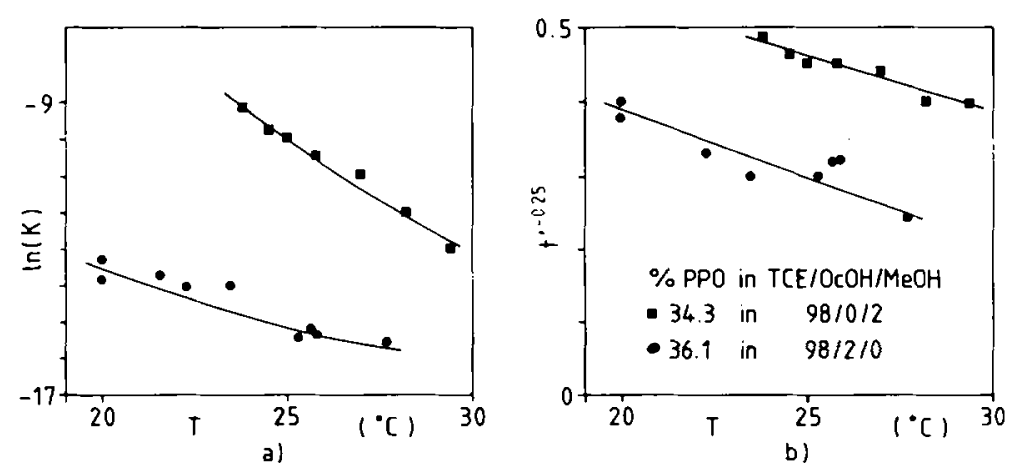

Fig. 12. Growth constant $K(a)$ and induction time $t^{\prime}(\mathrm{b})$ as a function of the crystallization temperature, $t^{\prime}$ in $\mathbf{s}$. 
of $\mathrm{OcOH}$ in the casting solution is varied and the ultrafiltration ${ }^{3}$ and gas separation ${ }^{13}$ properties of the resulting membranes are examined. In the next section these results are discussed.

In addition to the experiments of Broens and Buys, we prepared membranes from casting solutions with a constant TCE/OcOH ratio of 78/22 and with PPO concentrations varying from 6 to 8, 9, and 10\%. Micrographs of the top surface of the membranes are shown in Figure 13. It is clear that the porosity of the top layer decreases if the PPO concentration increases and that the porous structure is the result of liquid-liquid demixing. At a PPO concentration of $10 \%$ no pores could be detected at a magnification of $100,000 \times$, indicating that the pore radius is smaller than $50 \AA$.

\section{PREPARATION AND PROPERTIES OF PPO MEMBRANES}

The PPO membranes permeability data prepared by Broens ${ }^{3}$ and by Buys $^{13}$ are summarized in Table III. It is clear that an increase in initial $\mathrm{OcOH}$ content of the casting solutinn leads to membranes with a more open structure. For OcOH/TCE ratios lower than 18/82 the membranes have gas separation properties and no water flux is obtained under ultrafiltration conditions. The ideal or highest attainable $\mathrm{O}_{2} / \mathrm{N}_{2}$ separation factor with PPO membranes is about $5.0,{ }^{14}$ so the gas separation membranes are not completely tight: convective transport takes place through defects or very small pores. At a OcOH/TCE ratio of $18 / 82$ the membrane becomes permeable to water and shows no selectivity in $\mathrm{O}_{2} / \mathrm{N}_{2}$ separation. Upon increasing the $\mathrm{OcOH} / \mathrm{TCE}$ ratio to $22 / 78$ the water permeability increases, and since PPO is a hydrophobic polymer, the transport of water must take place through distinct pores.

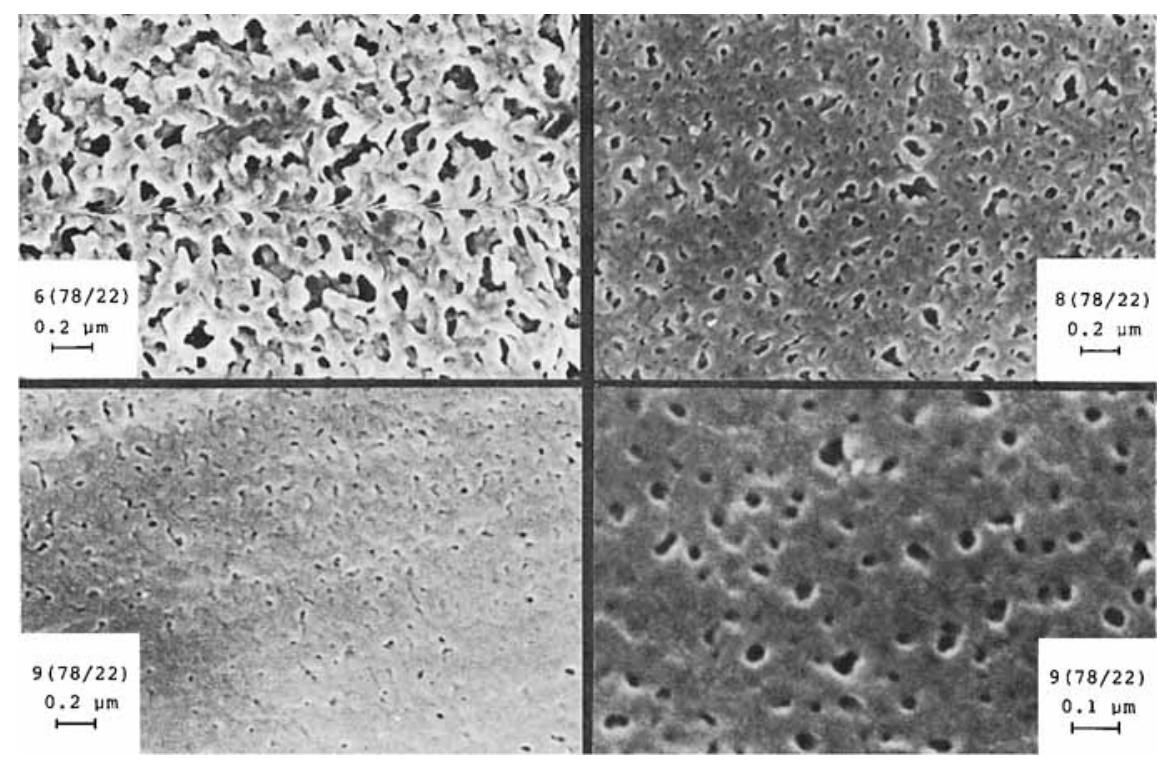

Fig. 13. Micrographs of top surface of PPO membranes. Labels indicate composition of casting solution: \%PPO(\% TCE/\%OcOH). Coagulation bath: MeOH. 
TABLE III

Permeation Characteristics of PPO Membranes; Casting Solution 10\% PPO in OcOH/TCE; Coagulation Bath $\mathrm{MeOH}$

\begin{tabular}{cccc}
\hline $\begin{array}{c}\text { \% OCOH/\% } \\
\text { TCE }\end{array}$ & $\begin{array}{c}J_{w i}{ }^{*} \\
(\mathrm{~cm} / \mathrm{h})\end{array}$ & $\begin{array}{c}10+12 P_{\mathrm{O}_{2}}{ }^{\mathrm{b}} \\
{\left[\left(\mathrm{m}^{3} / \mathrm{s}\right) /\left(\mathrm{m}^{2} \mathrm{~N} / \mathrm{m}^{2}\right)\right]}\end{array}$ & $a_{\mathrm{O}_{2} / \mathrm{N}_{2}{ }^{\mathrm{c}}}$ \\
\hline $0 / 100$ & 0 & & \\
$5 / 95$ & 0 & 10 & 4.0 \\
$10 / 90$ & 0 & 20 & 2.9 \\
$15 / 85$ & 0 & 270 & 1.8 \\
$18 / 82$ & $<0.5$ & $>10,000$ & 1.0 \\
$20 / 80$ & $1-2$ & & \\
$22 / 78$ & $5-25$ & & \\
\hline
\end{tabular}

- Steady state, pure water flux at a pressure difference of $3 \mathrm{~atm}^{3}$

${ }^{b}$ Oxygen permeability. ${ }^{13}$

'Selectivity for oyxgen in oxygen/nitrogen separation. ${ }^{13}$

Broens $^{3}$ formulated a hypothesis in which the addition of $\mathrm{OcOH}$ favors the crystallization of the PPO and leads to a more open structure of gelled PPO layers. However, the results of the PICS experiments do not show a significant effect of $\mathrm{OcOH}$ on the crystallization kinetics. This poses the question of whether another mechanism can explain the drastic influence of $\mathrm{OcOH}$ on the membrane properties.

In Figure 14 the locations of the casting-solution compositions are drawn in the ternary $\mathrm{PPO} / \mathrm{TCE} / \mathrm{OcOH}$ phase diagram. The points at the line of constant PPO concentration (10)\% represent the casting solutions employed by Broens and Buys. An increase in $\mathrm{OcOH}$ content brings the composition nearer to the liquid-liquid demixing gap. In fact, a casting solution with $\mathrm{OcOH} / \mathrm{TCE}$ ratio equal to $22 / 78$ is thermodynamically unstable at $22^{\circ} \mathrm{C}$, and this may account for the large variation in water permeability reported by Broens ${ }^{3}$ for the resulting membranes (cast at "room temperature").

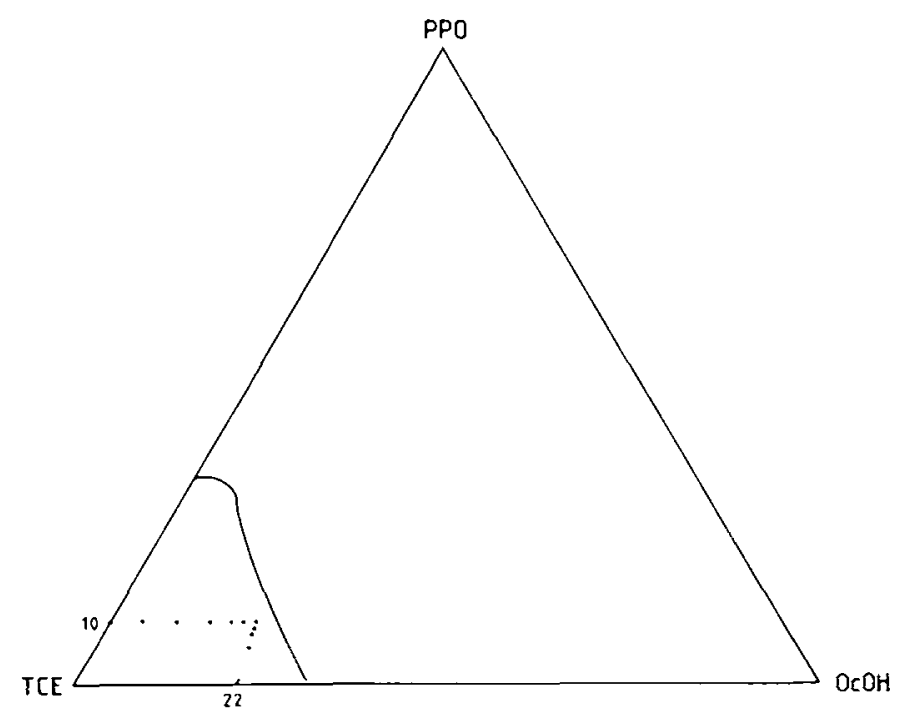

Fig. 14. Composition of casting solutions in the ternary PPO/TCE/OCOH phase diagram; see text. 
When the casting solution is immersed in the $\mathrm{MeOH}$ bath, TCE and $\mathrm{OcOH}$ diffuse into the bath and the PPO concentration increases. The penetration of the $\mathrm{MeOH}$ into the film moves the liquid-liquid demixing boundary to the left in the phase diagram, as can be seen from Figure 5. As we deal with a quaternary system it is very difficult to visualize the coagulation by coagulation paths, but we think it is plausible that an increase in initial $\mathrm{OcOH}$ content favors the occurence of liquid-liquid demixing in the film. Evaluating the permeability data of Table III, we suggest that for initial $\mathrm{OcOH} / \mathrm{TCE}$ ratios up to $18 / 82$ the top layer is a dense gelled layer the thickness of which decreases with increasing $\mathrm{OcOH}$ concentration. If the $\mathrm{OcOH} / \mathrm{TCE}$ ratio is $18 / 82$ or higher, small pores are present in the top layer owing to liquid-liquid demixing and the pore radius probably increases with increasing $\mathrm{OcOH}$ concentration. The micrographs of Figure 13 support the hypothesis of liquid-liquid demixing in the top layer if the $\mathrm{OcOH}$ concentration is high.

A question not yet addressed is whether crystallization plays a role in the formation of PPO membranes. It is clear that gelation in PPO systems is accompanied and probably induced by crystallization. However, the increase in PPO concentration, especially in the top layer, is so rapid that the crystalline entities are probably not larger than the size of a stable nucleus: a dried PPO ultrafiltration membrane shows no or a very small melting peak upon heating in a DSC experiment. In the case of homogeneous PPO membranes the interplay of precipitation rate and crystallization kinetics determined the mechanical stability of the film. A solution of $10 \%$ PPO in TCE cast with a thickness of $0.1 \mathrm{~mm}$ yields upon evaporation of the TCE a film with excellent mechanical properties: flexible and strong. If the evaporation rate is slowed down or if the casting thickness is increased the film becomes stiff and brittle owing to its higher degree of crystallinity.

\section{References}

1. C. A. Smolders, in Ultrafiltration Membranes and Applications, A. R. Cooper, Ed., Plenum, New York, 1980.

2. Y. G. Wÿmans, Ph. D. thesis, Twente University of Technology, 1984, Chapter 2 (Y. G. Wÿmans and C. A. Smolders).

3. L. Broens, D. M. Koenhen, and C. A. Smolders, Desalination, 22, 205 (1977).

4. M. Avrami, J. Chem. Phys., 7, 1103 (1939); 8, 212 (1940); 9, 177 (1941).

5. D. Turnbull, Solid State Physics, Academic, New York, 1956, Vol. 3.

6. J. B. Zeldovich, Acta Physicichem. USSR, 1, 1 (1943).

7. G. Oster, J. Colloid Sci, B9, 435 (1974).

8. J. G. Wijmans, Ph.D. thesis, Twente University of Technology, 1984, Chapter 3, (J. G. Wijmans, J. Kant, M. H. V. Mulder, and C. A. Smolders), Polymer, to appear.

9. M. Gordon, J. Goldsbrough, and J. W. Kennedy, J. Polym. Sci. Polym. Symp., 61, 199 (1977).

10. K. Derham, J. Goldsbrough, and M. Gordon, Pune Appl. Chem., 38, 97 (1974).

11. D. M. Koenhen, C. A. Smolders, and M. Gordon, J. Polym. Sci. Polym. Symp., 93, 61 (1978).

12. F. E. Karasz and J. M. O'Reilly, Polym. Lett., 3, 561 (1965).

13. H. C. W. M. Buys, A. E. Jansen, H. F. van Wijk, D. Bargeman, and C. A. Smolders, presented at the Third Symposium on Synthetic Membranes in Science and Industry, Tuibingen, 1981.

14. W. Pusch and A. Walch, Angew. Chem., 21, 660 (1982).

Received October 29, 1984

Accepted March 27, 1985 